International Journal of Translational

Medical Research and Public Health (2020), Volume 4, Issue 2, I62-169

\begin{tabular}{ll}
\hline & INTERNATIONAL JOURNAL OF TRANSLATIONAL \\
& MEDICAL RESEARCH AND PUBLIC HEALTH \\
& ISSN: 2576-9499 (Online) \\
& ISSN: 2576-9502 (Print) \\
I]TMRPH & Available online at www.jijmrph.org $10.21106 /$ ijtmrph.206 \\
\hline
\end{tabular}

ORIGINALARTICLE | CANCER MORTALITY

\title{
Association of Happiness and Life Satisfaction with Cancer Mortality in the United States: A Longitudinal Analysis
}

\author{
Hyunjung Lee, PhD, MPP, MBA ${ }^{\square}$; Gopal K. Singh, PhD, MS, MSc ${ }^{2}$ \\ 'Oak Ridge Institute for Science and Education (ORISE), Oak Ridge,TN 3783I, USA; ${ }^{2}$ U.S. Department of Health and Human Services, Health Resources \\ and Services Administration, Office of Health Equity, 5600 Fishers Lane, Rockville, MD 20857, USA \\ Corresponding author email: hyunjung.lee000I@gmail.com
}

ABSTRACT

Background: The impact of happiness and life satisfaction on cancer mortality is not well studied. Using a longitudinal dataset, we examined the association between levels of happiness/life satisfaction and cancer mortality in the United States.

Methods: We analyzed the 200I National Health Interview Survey (NHIS) prospectively linked to 200 I2014 mortality records in the National Death Index (NDI) $(\mathrm{N}=30,933)$. Cox proportional hazards regression was used to model survival time as a function of happiness, life satisfaction, and sociodemographic and behavioral characteristics.

Results: In Cox models with 14 years of mortality follow-up, cancer mortality risk was $78 \%$ higher (hazard ratio $[H R]=I .78 ; 95 \% \mathrm{Cl}=1.42,2.23)$ in adults with little or no happiness, controlling for age, and $53 \%$ higher $(\mathrm{HR}=\mathrm{I} .53 ; 95 \% \mathrm{Cl}=\mathrm{I} .19, \mathrm{I} .97)$ in adults with little/no happiness, controlling for sociodemographic, behavioral and health characteristics, when compared with adults reporting happiness most or all of the time. Ageadjusted cancer mortality risk increased by $4 I \%(\mathrm{HR}=\mathrm{I} .4 \mathrm{I} ; 95 \% \mathrm{Cl}=\mathrm{I} .2 \mathrm{I}, \mathrm{I} .77)$ in adults who were very dissatisfied with their life. Cancer mortality did not vary by life satisfaction after adjusting for all covariates.

Conclusions and Implications for Translation: Adults with lower happiness levels had significantly higher cancer mortality risks than those with higher happiness levels. Excess mortality was substantially accounted for by sociodemographic, behavioral, and health risk factors.

Keywords: • Happiness • Life satisfaction • Cancer • Mortality • Longitudinal • Social determinants

Copyright () 2020 Lee and Singh. Published by Global Health and Education Projects, Inc.This is an open-access article distributed under the terms of the Creative Commons Attribution License CC BY 4.0.

\section{Introduction}

Cancer is the second leading cause of death in the United States and globally, and is responsible for an estimated 600,000 deaths in the US and 9.6 million deaths globally. ${ }^{1,2}$ Race/ethnicity, socioeconomic status (SES), smoking, diet, alcohol use, obesity, physical inactivity, reproductive behavior,occupational and environmental exposures, human papillomavirus 
(HPV) and Helicobacter pylori infections, limited cancer screening, and reduced access to health care are well-known risk factors for cancer outcomes. ${ }^{3}$ However, the association of cancer with another possible risk factor, subjective well-being, measured by happiness and life satisfaction, is not well studied. Despite being one of the wealthiest nations, the US ranks lower than 17 other countries in happiness and life satisfaction. ${ }^{4,5}$ Happiness and life satisfaction have been shown to be protective factors for physical health, morbidity, and mortality. ${ }^{5-10}$ However, studies examining the association between subjective wellbeing and cancer mortality are limited, particularly in the US. ${ }^{7}$ To address this gap in research on cancer, we examined the association between happiness/ life satisfaction and US cancer mortality by using longitudinal data and by considering a wide range of sociodemographic, behavioral, and health risk factors.

\section{Methods}

The data source for this study was the 200I National Health Interview Survey (NHIS) prospectively linked to the death certificate data from the National Death Index (NDI)." NHIS is a nationally representative, cross-sectional household interview survey that provides socio-economic, demographic, and health characteristics of the US civilian, non-institutionalized population. We used the public-use linked NHIS-NDI mortality file, developed by the National Center for Health Statistics, that includes mortality followup from the date of survey participation in $200 \mathrm{I}$ through December 31, 2014.'2

The study sample consisted of 31,376 adults aged $\geq 18$ years in the 200I NHIS sample adult file.The sample ineligible for mortality follow-up was eliminated from the analysis. Approximately $1.41 \%$ of the sample had missing data on happiness and life satisfaction, which were also excluded from the analysis. The final eligible sample size was 30,933 . All covariates except poverty status had $<1.8 \%$ of missing cases.About $21.7 \%$ of the cases had missing data on poverty status for which we included a covariate category in the analysis to avoid losing a large number of observations.

Our outcome of interest was cancer mortality (ICD-I0 codes C00-C97). Follow-up time for individuals who died was defined by the number of months from the month/year of interview to the month/year of death. Since NHIS-NDI provides only the quarter of death, we assumed that death occurred in the middle of the quarter, February, May, August, or November.

The independent variables were happiness and life satisfaction. The level of happiness was measured by responses to the question, "During the past 30 days, how often did you feel happy?" Happiness was categorized by none or a little of the time, some of the time, and most or all of the time. Life satisfaction was measured by responses to the question, "In general, how satisfied are you with your life?" Life satisfaction was categorized by very dissatisfied or dissatisfied, satisfied, and very satisfied.

Based on previous research, we selected the following covariates for modeling: age, gender, race/ethnicity, nativity/immigrant status, marital status, social support, education, poverty status, homeownership, region, activity limitation, body mass index (BMI), smoking status, and alcohol use..$^{5,6}$

We computed age-adjusted mortality rates per 100,000 person-years of exposure by happiness and life satisfaction levels. ${ }^{13}$ Cox proportional hazards regression models were used to derive relative risks of mortality, controlling for individual characteristics. ${ }^{13}$ Individuals surviving beyond the follow-up period and those dying from other causes were treated as right-censored observations. All analyses were conducted by Stata 15, accounting for complex survey design effects. ${ }^{14}$

\section{Results}

Approximately $4.5 \%$ of the sample responded that they felt happy none or a little of the time during the past 30 days. About $5.9 \%$ of the sample responded that they were very dissatisfied or dissatisfied with their life in general. Women reported lower levels of happiness and life satisfaction than men (Table I).

Adults with lower levels of happiness and life satisfaction had higher age-adjusted cancer mortality rates (Figure I). The cancer mortality rate for adults with "none or a little of the time" happiness was 444.0 deaths per 100,000 person-years, 55\% higher than the mortality rate of $\mathbf{2 8 7 . 3}$ for adults 
with "most or all of the time" happiness. The cancer mortality rate for adults who were very dissatisfied or dissatisfied with their life was $26 \%$ higher than the rate for those who were very satisfied.

In Cox models, the age-adjusted cancer mortality risk was $78 \%$ higher (hazard ratio $[H R]=I .78$; $95 \% \mathrm{Cl}=1.42,2.23)$ in adults with "none or a little of the time" happiness, compared with adults with "most or all of the time" happiness (Table I, Model I). After controlling for socioeconomic and demographic covariates, the mortality risk was $68 \%$ higher $(\mathrm{HR}=\mathrm{I} .68 ; 95 \% \mathrm{Cl}=\mathrm{I} .34,2 . \mathrm{II})$ in adults with "none or a little of the time" happiness, compared with adults with "most or all of the time" happiness (Table I, Model 2).After controlling for all covariates, the mortality risk was $53 \%$ higher $(H R=1.53$; $95 \%$ $\mathrm{Cl}=\mathrm{I} .19, \mathrm{I} .97)$ in adults with "none or a little of the time" happiness, compared to those with "most or all of the time" happiness (Table I, Model 3).

In Cox models, the age-adjusted cancer mortality risk was $4 I \%$ higher $(\mathrm{HR}=I .4 I ; 95 \% \mathrm{Cl}=\mathrm{I} .12, \mathrm{I} .77)$ among adults who were very dissatisfied or dissatisfied with their life, compared with adults who were very satisfied (Table I, Model I). After controlling for socioeconomic and demographic covariates, the cancer mortality risk was $26 \%$ higher $(\mathrm{HR}=\mathrm{I} .26 ; 95 \% \mathrm{Cl}=0.99, \mathrm{I} .60)$ in adults who were very dissatisfied or dissatisfied, compared with adults who were very satisfied (Table I, Model 2). After controlling for all covariates, cancer mortality did not vary by life satisfaction (Table I, Model 3). The association between happiness and fully-adjusted cancer mortality risks was stronger for men than for women (Table I).

We tested the issue of reverse causality by comparing the analysis between the samples with and without baseline histories of cancer diagnoses. We found in the fully-adjusted models no association between life satisfaction and cancer mortality for both respondents with and without cancer. While the association between happiness and cancer mortality was statistically significant among both

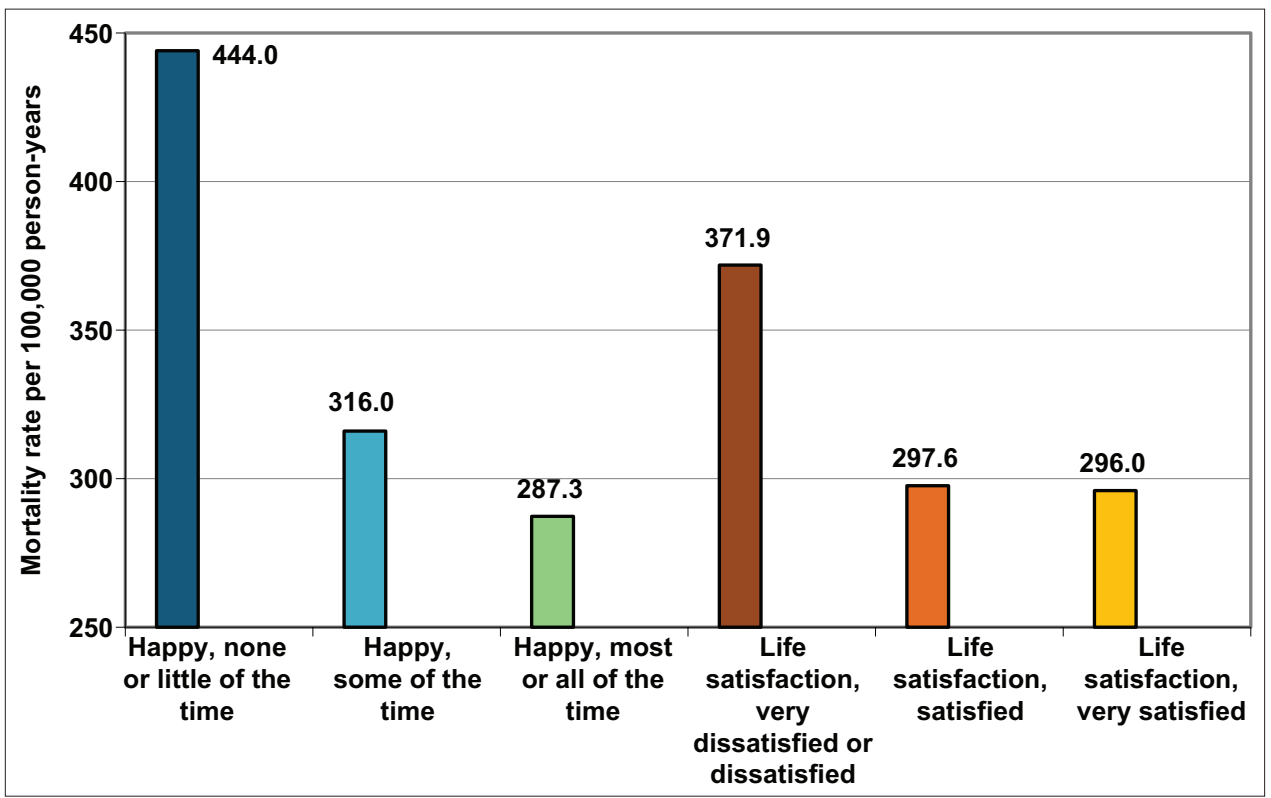

Figure I: Age-Adjusted Cancer Mortality Rates per 100,000 Person-Years by Levels of Happiness and Life Satisfaction, United States, 200I-20I4

Source: Data derived from the 200I-20I4 NHIS-NDI Record Linkage Study. The mortality rate ratio between low and high happiness levels, none/little of the time and most/all of the time was $\mathrm{RR}=1.55 ; 95 \% \mathrm{Cl}=1.23, \mathrm{I} .86 ; \mathrm{p}<0.0 \mathrm{I}$. The mortality rate ratio between low and high life satisfaction levels, was $R R=1.26 ; 95 \% \mathrm{Cl}=1.00,1.52 ; p<0.05$ 
Table I.Age-adjusted and covariate-adjusted hazard ratios (HRs) for cancer mortality among adults aged $\geq I 8$ years, United States, 200 I-20 I 4

\begin{tabular}{|c|c|c|c|c|}
\hline & \multirow{2}{*}{$\begin{array}{c}\text { Sample size } \\
\begin{array}{l}\text { Observations } \\
\text { (weighted \%) }\end{array}\end{array}$} & \multicolumn{3}{|c|}{ Cox model HR (95\% ci) } \\
\hline & & $\begin{array}{c}\text { Age-adjusted } \\
\text { model' }\end{array}$ & $\begin{array}{c}\text { SES-adjusted } \\
\text { model }^{2}\end{array}$ & $\begin{array}{l}\text { Fully-adjusted } \\
\text { model }^{3}\end{array}$ \\
\hline \multicolumn{5}{|l|}{ Both sexes combined } \\
\hline Cancer deaths & $\mathrm{I}, 305$ & & & \\
\hline Happiness & 30,933 & & 30,933 & \\
\hline None / a little of the time & $\mathrm{I}, 575(4.46)$ & $1.78 * * * 4(1.42,2.23)$ & $1.68 * * *(1.34,2.11)$ & $1.53 * * *(1.19,1.97)$ \\
\hline Some of the time & $5,603(16.88)$ & I.I8* $(0.99,1.4)$ & $1.16 *(0.98,1.38)$ & I.II (0.92,I.35) \\
\hline Most or all of the time & $23,755(78.65)$ & 1.00 (Reference) & 1.00 (Reference) & I.00 (Reference) \\
\hline Life satisfaction $^{5}$ & 30,928 & & 30,928 & \\
\hline $\begin{array}{l}\text { Very dissatisfied or } \\
\text { dissatisfied }\end{array}$ & $2,109(5.92)$ & $1.4 \mid * * *(I .|2| 1.77)$, & $1.26 *(0.99,1.60)$ & I. I $3(0.87$, I.47) \\
\hline Satisfied & $16,115(50.20)$ & $1.09(0.95,1.25)$ & $\mathrm{I} .05(0.92, \mathrm{I} .2 \mathrm{I})$ & $1.03(0.89,1.19)$ \\
\hline Very satisfied & I2,704 (43.88) & I.00 (Reference) & I.00 (Reference) & I.00 (Reference) \\
\hline \multicolumn{5}{|l|}{ Male } \\
\hline Happiness & 13,463 & & 13,463 & \\
\hline None / a little of the time & $649(4.21)$ & $2.02 * * *(1.49,2.74)$ & $1.93 * * *(1.42,2.61)$ & $1.90 * * *(1.37,2.63)$ \\
\hline Some of the time & $2,352(16.36)$ & $1.20(0.94,1.53)$ & $1.20(0.94, I .53)$ & $1.25(0.96,1.63)$ \\
\hline Most or all of the time & $10,462(79.43)$ & I.00 (Reference) & I.00 (Reference) & I.00 (Reference) \\
\hline Life satisfaction & 13,462 & & 13,462 & \\
\hline $\begin{array}{l}\text { Very dissatisfied or } \\
\text { dissatisfied }\end{array}$ & $868(5.64)$ & $1.63^{* * *}(1.18,2.26)$ & $1.4 I *(1.00,1.97)$ & I.33 $(0.94,1.88)$ \\
\hline Satisfied & $6,959(49.98)$ & $\mathrm{I} .03(0.85, \mathrm{I} .25)$ & $0.98(0.81,1.19)$ & $0.99(0.81, I .20)$ \\
\hline Very satisfied & $5,635(44.38)$ & 1.00 (Reference) & 1.00 (Reference) & I.00 (Reference) \\
\hline \multicolumn{5}{|l|}{ Female } \\
\hline Happiness & 17,470 & & 17,470 & \\
\hline None / a little of the time & $926(4.69)$ & $1.54 * *(1.09,2.18)$ & $1.35 *(0.95,1.93)$ & I.I3 $(0.78,1.65)$ \\
\hline Some of the time & $3,251(17.37)$ & $1.23 *(0.97,1.55)$ & I. I $3(0.90,1.42)$ & $1.00(0.77,1.29)$ \\
\hline Most or all of the time & 13,293 (77.94) & I.00 (Reference) & I.00 (Reference) & I.00 (Reference) \\
\hline Life satisfaction & 17,466 & & 17,466 & \\
\hline $\begin{array}{l}\text { Very dissatisfied or } \\
\text { dissatisfied }\end{array}$ & $I, 24 \mid(6.17)$ & $1.38 *(1,1.92)$ & I.I $3(0.80,1.6 I)$ & $0.94(0.65,1.37)$ \\
\hline Satisfied & $9,156(50.41)$ & $1.25^{* *}(1.04,1.5 \mathrm{I})$ & $1.16(0.96,1.4)$ & $1.08(0.88, I .33)$ \\
\hline Very satisfied & $7,069(43.42)$ & I.00 (Reference) & I.00 (Reference) & I.00 (Reference) \\
\hline
\end{tabular}

samples, the effect sizes were greater for individuals with cancer history $(\mathrm{HR}=2.09 ; 95 \% \mathrm{Cl}=1.27,3.44$, $\mathrm{P}<0.0 \mathrm{I}$ for those with cancer history; $H R=1.27$; $95 \% \mathrm{Cl}=0.96,1.68, \mathrm{p}<0.10$ for those without cancer history) [Table 2].
We conducted sensitivity analyses to evaluate temporal robustness of happiness/life satisfaction by re-estimating models using 2-year, 5-year, and 10 year follow-up times. The longer follow-up dilutes the mortality impact of baseline happiness and life 
Lee and Singh International Journal of Translational Medical Research and Public Health (2020), Vol. 4, No. 2, I62-I69

Table 2. Age-adjusted and covariate-adjusted hazard ratios (HRs) for cancer mortality among adults aged $\geq \mid>8$ years with and without a history of cancer diagnosis at baseline, 200 I-20 I4

\begin{tabular}{|c|c|c|c|}
\hline & Age-adjusted model & SES-adjusted model & Fully-adjusted model \\
\hline \multicolumn{4}{|c|}{ Adults without the cancer diagnosis at baseline } \\
\hline Happiness & 28,732 & 28,732 & 28,732 \\
\hline None / a little of the time & $1.59 * * *(1.22,2.08)$ & $1.47 * * *(1.12,1.92)$ & $1.27 *(0.96,1.68)$ \\
\hline Some of the time & I.06 $(0.87,1.30)$ & $\mathrm{I} .04(0.85, \mathrm{I} .27)$ & $0.95(0.76,1.19)$ \\
\hline Most or all of the time & I.00 (Reference) & I.00 (Reference) & I.00 (Reference) \\
\hline Life satisfaction & 28,729 & 28,729 & 28,729 \\
\hline Very dissatisfied or dissatisfied & $1.43 * * *(1.10,1.85)$ & $1.25 *(0.96,1.64)$ & $\mathrm{I} .07(0.79, \mathrm{I} .44)$ \\
\hline Satisfied & $1.10(0.94,1.29)$ & $1.06(0.90,1.24)$ & $\mathrm{I} .0 \mathrm{I}(0.86, \mathrm{I} .20)$ \\
\hline Very satisfied & I.00 (Reference) & I.00 (Reference) & I.00 (Reference) \\
\hline \multicolumn{4}{|c|}{ Adults with the cancer diagnosis at baseline } \\
\hline Happiness & 2,201 & 2,201 & 2,201 \\
\hline None / a little of the time & $2.13 * * *(1.43,3.16)$ & $2.04 * * *(1.34,3.10)$ & $2.09 * * *(1.27,3.44)$ \\
\hline Some of the time & $1.42 * *(1.05,1.93)$ & $1.38 * *(1.02,1.86)$ & $1.44 * *(1.05,1.99)$ \\
\hline Most or all of the time & I.00 (Reference) & I.00 (Reference) & I.00 (Reference) \\
\hline Life satisfaction & 2,199 & 2,199 & 2,199 \\
\hline Very dissatisfied or dissatisfied & $1.22(0.77,1.94)$ & $1.15(0.72, \mathrm{I} .84)$ & $1.16(0.69,1.97)$ \\
\hline Satisfied & $\mathrm{I} .07(0.83, \mathrm{I} .37)$ & $1.02(0.78, \mid .32)$ & $1.04(0.78,1.39)$ \\
\hline Very satisfied & I.00 (Reference) & I.00 (Reference) & I.00 (Reference) \\
\hline
\end{tabular}

Data derived from the 200I-20I4 NHIS-NDI Record Linkage Study. ${ }^{* * *} \mathrm{p}<0.0$ I; ${ }^{* *} \mathrm{p}<0.05 ;{ }^{*} \mathrm{p}<0.10$

satisfaction, as they are expected to differ from their baseline levels over the longer follow-up (Table 3).

\section{Discussion}

In this prospective study of 30,933 US adults using 14 years of mortality follow-up data, we found that adults with lower levels of happiness and life satisfaction Implies causality of age-adjusted cancer mortality. After controlling for several sociodemographic, health status, and behavioral characteristics, significantly higher risks of cancer mortality existed for adults who did not experience happiness, compared with those who reported happiness most or all of the time. No significant association was found between life satisfaction and cancer mortality after adjusting for covariates. Our study contributes to the empirical literature by showing an inverse relationship between happiness/ life satisfaction and cancer mortality.

Our study findings are compatible with those from previous studies. ${ }^{5,7-10}$ Martin-Maria and colleagues found that the pooled HR for the effect of subjective well-being, including happiness and life satisfaction, on all-cause mortality was $0.92(95 \% \mathrm{Cl}=0.9 \mathrm{l}, 0.93)$ in their meta-analysis of 90 studies. ${ }^{7}$ One study found an association between unhappiness and cancer mortality among UK women aged 50-69 in the ageadjusted model $(\mathrm{HR}=\mathrm{I} .13$; $95 \% \mathrm{Cl}=\mathrm{I.08}, \mathrm{I} . \mathrm{I8})$, but the association disappeared after adjustment for socioeconomic and health characteristics. ${ }^{8}$ We found similar patterns for women. The age-adjusted relative risk of cancer mortality associated with happiness was 1.54 , which became statistically insignificant in the fully-adjusted model.

Our study shows a statistically significant link between happiness and cancer mortality, but does not shed light on behavioral or biological mechanisms through which happiness or life satisfaction might affect cancer mortality. One potential mechanism is that individuals with greater happiness/life satisfaction levels have healthier lifestyles, including greater physical activity, higher consumption of fruits and vegetables, less drinking or smoking, and more preventive care such as higher uptake of 
Table 3. Age-adjusted and covariate-adjusted hazard ratios (HRs) for cancer mortality by different follow-up times among US adults aged $\geq 18$ years, $200 \mathrm{I}-2014$

\begin{tabular}{|c|c|c|c|}
\hline & Age-adjusted model & SES-adjusted model & Fully-adjusted model \\
\hline \multicolumn{4}{|l|}{ 2-Year mortality follow-up } \\
\hline \multicolumn{4}{|l|}{ Happiness } \\
\hline None / a little of the time & $2.30 * * *(1.27,4.18)$ & $2.27 * * *(1.23,4.19)$ & $2.53 * * *(1.28,5.02)$ \\
\hline Some of the time & $2.06 * * *(1.40,3.01)$ & $2.06 * * *(1.39,3.04)$ & $2.15 * * *(1.39,3.33)$ \\
\hline Most or all of the time & I.00 (Reference) & I.00 (Reference) & 1.00 (Reference) \\
\hline \multicolumn{4}{|l|}{ Life satisfaction } \\
\hline Very dissatisfied or dissatisfied & $1.92 * *(1.05,3.5 \mathrm{I})$ & $1.74 *(0.93,3.25)$ & $1.83 *(0.92,3.65)$ \\
\hline Satisfied & I.2I $(0.85,1.72)$ & I.I $8(0.82, \mid .7 I)$ & $1.19(0.81,1.75)$ \\
\hline Very satisfied & I.00 (Reference) & I.00 (Reference) & I.00 (Reference) \\
\hline \multicolumn{4}{|l|}{ 5-Year mortality follow-up } \\
\hline \multicolumn{4}{|l|}{ Happiness } \\
\hline None / a little of the time & $2.33 * * *(1.65,3.29)$ & $2.23 * * *(1.55,3.20)$ & $2.17 * * *(1.47,3.21)$ \\
\hline Some of the time & $1.40 * *(1.07,1.83)$ & $1.39 * *(1.06,1.83)$ & $1.40 * *(1.04,1.88)$ \\
\hline Most or all of the time & I.00 (Reference) & I.00 (Reference) & I.00 (Reference) \\
\hline \multicolumn{4}{|l|}{ Life satisfaction } \\
\hline Very dissatisfied or dissatisfied & $1.65 * * *(1.15,2.36)$ & $1.48 *(1.00,2.19)$ & $1.4 \mid(0.91,2.17)$ \\
\hline Satisfied & $\mathrm{I} .04(0.83, \mathrm{I} .30)$ & I.02 (0.82, I.28) & $\mathrm{I} .03(0.8 \mathrm{I}, \mathrm{I} .32)$ \\
\hline Very satisfied & I.00 (Reference) & I.00 (Reference) & I.00 (Reference) \\
\hline \multicolumn{4}{|l|}{ I0-Year mortality follow-up } \\
\hline \multicolumn{4}{|l|}{ Happiness } \\
\hline None / a little of the time & $2.01 * * *(1.52,2.65)$ & $1.93 * * *(1.44,2.57)$ & $1.8 * * *(1.33,2.44)$ \\
\hline Some of the time & I.I9* $(0.97,1.46)$ & $1.20 *(0.98, \mathrm{I} .47)$ & I.I $6(0.93,1.45)$ \\
\hline Most or all of the time & I.00 (Reference) & I.00 (Reference) & I.00 (Reference) \\
\hline \multicolumn{4}{|l|}{ Life satisfaction } \\
\hline Very dissatisfied or dissatisfied & $1.48 * * *(1.12,1.96)$ & $1.34 *(0.99,1.81)$ & $1.23(0.89,1.69)$ \\
\hline Satisfied & $1.05(0.89,1.23)$ & $\mathrm{I} .02(0.86, \mathrm{I} .20)$ & I.0I $(0.84,1.20)$ \\
\hline Very satisfied & 1.00 (Reference) & I.00 (Reference) & I.00 (Reference) \\
\hline
\end{tabular}

Source: Data derived from the 200I-2014 NHIS-NDI Record Linkage Study. ${ }^{* * *} \mathrm{p}<0.01$; ${ }^{* *} \mathrm{p}<0.05 ;{ }^{*} \mathrm{p}<0.10$

cancer screening, resulting in reduced morbidity and mortality risks. ${ }^{5}$ The other mechanism might involve biological processes of happiness relevant to health such as biomarker neuroendocrine, inflammation, carcinogenesis, metabolic, or allostatic load. ${ }^{5}$ There are many risk factors for happiness/life satisfaction, such as personality, genetics, stress exposure, social support or network, race/ethnicity, SES, marital status, physical activity, and health status. ${ }^{5}$ In our analysis, we controlled for several of these factors, which are associated with both happiness/ life satisfaction and cancer mortality in an expected manner. ${ }^{5,6}$ Further research is needed to examine differential associations between happiness or life satisfaction and cancer mortality by considering different pathways.

\section{I. Limitations}

This study has several limitations. First, residual confounding and reverse causality might have affected our study findings. While we controlled for self-reported health status, activity limitation, BMI, and smoking at baseline, there could have been other potential confounders such as neighborhood environments or periods of economic downturn. Chronic poor health itself may be a determinant 
of self-reported happiness and life satisfaction at the survey time. Although we controlled for several baseline health factors, the issue of reverse causation cannot be fully resolved. Second, NHIS's measures of happiness and life satisfaction might not capture all aspects of subjective well-being, including optimism, realization of personal potential and fulfillment of life goals or specific measures of happiness in such domains as marriage/family, jobs, and finances. Third, because the NHIS excludes the institutionalized population, who may have lower happiness/life satisfaction and higher mortality levels, cancer mortality risks associated with happiness/life satisfaction might have been underestimated. Fourth, deaths from specific cancer sites are not identified in the public-use NHIS-NDI database, which limits our analysis. Finally, all covariates in the NHIS-NDI database were time-invariant during the follow-up. Several covariates such as SES, health status, healthrisk behaviors, and happiness/life satisfaction could have varied over the 14-year follow-up, which would have influenced their estimated impacts on cancer mortality.

\section{Conclusions and Implications for Translation}

With 14 years of mortality follow-up in a nationally representative study of 30,933 US adults aged $\geq 18$ years, we found that people with low levels of happiness and life satisfaction had, respectively, $78 \%$ and $41 \%$ higher age-adjusted risks of cancer mortality compared to those with high levels of happiness and life satisfaction. The association between happiness and cancer mortality remained marked and statistically significant even after controlling for several sociodemographic, behavioral, and health characteristics. Our study findings indicate happiness and satisfaction to be an important predictor of cancer mortality; they underscore the significance of enhancing subjective well-being in the population as a potential strategy for reducing cancer mortality. Social determinants such as education, income, work status, job security, housing conditions, social support, social environment, and access to green spaces and quality health care are key to enhancing happiness and life satisfaction. Policies addressing these social determinants will not only promote happiness and well-being among people and but may also lead to reductions in cancer mortality.

\section{Ethical Consideration}

Conflict of Interest: The authors declare no conflict of interest. Funding source: Dr. Hyunjung Lee was supported in part by an appointment to the Research Participation Program at the Health Resources \& Services Administration - Office of Health Equity (HRSA-OHE) and Office of Planning, Analysis and Evaluation (HRSA-OPAE), administered by the Oak Ridge Institute for Science and Education (ORISE) through an interagency agreement between the US Department of Energy and HRSA. Disclaimer: The views expressed in this publication are solely the opinions of the authors and do not necessarily reflect the official policies of US Department of Health and Human Services, Health Resources and Services Administration, nor does mention of the department or agency names imply endorsement by the US Government. Financial Disclosure: The authors have no financial relationships relevant to this article to disclose. Ethical approval: The study was deemed exempt from Institutional Review Board approval as it utilized a de-identified public use dataset.

\section{Key Messages}

Using a national longitudinal dataset with 14-years of mortality follow-up of 30,933 US adults, this study estimated the effects of various levels of happiness and life satisfaction on cancer mortality.

People with low levels of happiness and life satisfaction had, respectively, $78 \%$ and $41 \%$ higher age-adjusted risk of cancer mortality compared with those reporting high levels of happiness and life satisfaction.

The association between happiness and cancer mortality was stronger for men than for women. Social determinants such as race/ethnicity, education, income, employment status, marital status, immigrant status, social support, activity limitation, and health-risk factors of smoking, obesity, and alcohol use largely accounted for the excess cancer mortality associated with low 
levels of happiness and life satisfaction. However, the association between happiness and cancer mortality remained marked and statistically significant even after controlling for these factors. Happiness is an important predictor of cancer mortality. Policies aimed at promoting happiness and well-being among people by addressing social determinants may lead to reductions in cancer mortality.

\section{References}

I. Xu J, Murphy SL, Kochanek KD, Arias E. Mortality in the United States, 20 I8. NCHS Data Brief. 2020;355: I-7.

2. World Health Organization. Fact Sheet: Cancer. https:// www.who.int/news-room/fact-sheets/detail/cancer. Published September 12, 20I8.Accessed June 7, 2020.

3. Singh GK, Jemal A. Socioeconomic and racial/ ethnic disparities in cancer mortality, incidence, and survival in the United States, 1950-2014: over six decades of changing patterns and widening inequalities. J Environ Public Health. 2017:2819372. doi: 10.1 I55/2017/2819372

4. Helliwell J, Layard R, Sachs J, De Neve JE, eds. World Happiness Report 2020. Sustainable Development Solutions Network; 2020.

5. Steptoe A. Happiness and health. Annu Rev Public Health. 2019;40(1):339-359. doi:10.1 146/annurevpublhealth-040218-044I50

6. Siahpush M, Spittal M, Singh GK. Happiness and life satisfaction prospectively predict self-rated health, physical health, and the presence of limiting, long-term health conditions. Am J Health Promot. 2008;23(I): 18-26. doi: I0.4278/ajhp.061023। 37

7. Martín-María N, Miret M, Caballero FF, et al. The impact of subjective well-being on mortality: a meta-analysis of longitudinal studies in the general population. Psychosom Med. 2017;79(5):565-575.doi: 10.1097/PSY.0000000000000444
8. Liu B, Floud S, Pirie K, Green J, Peto R Beral V; Million Women Study Collaborators. Lancet. 2016;387(1002I):874-88I. doi: I0.1016/S0I406736(15)01087-9

9. Diener E, Chan MY. Happy people live longer: Subjective well-being contributes to health and longevity. Appl Psychol Health Well-Being. doi: 10.1III/j. 1758-0854.2010.01045.x

10. Veenhoven R. Healthy happiness: effects of happiness on physical health and the consequences for preventive health care. J Happiness Stud. 2008;9(3):449-469. doi: I0.1007/s 10902-006-9042-I

II. Blewett LA, Rivera Drew JA, King ML WK. National health interview survey: version 6.4 [dataset]; 2019. IPUMS Health Surveys. doi:https://doi.org//0.18128/ D070.V6.4. Accessed June 7, 2020.

12. Centers for Disease Control and Prevention. 2015 Public-Use Linked Mortality Files. National Center for Health Statistics; 2015.

13. Namboodiri K, Suchindran CM. Life table techniques and their applications. In: Winsborough $\mathrm{HH}$, series ed. Studies in Population. Academic Press; 1987.

14. Stata Corp (2017) Stata Statistical Software: Release 15. College Station, TX: StataCorp LLC.

\section{PUBLISH IN THE}

International Journal of Translational Medical Reasearch and Public Health

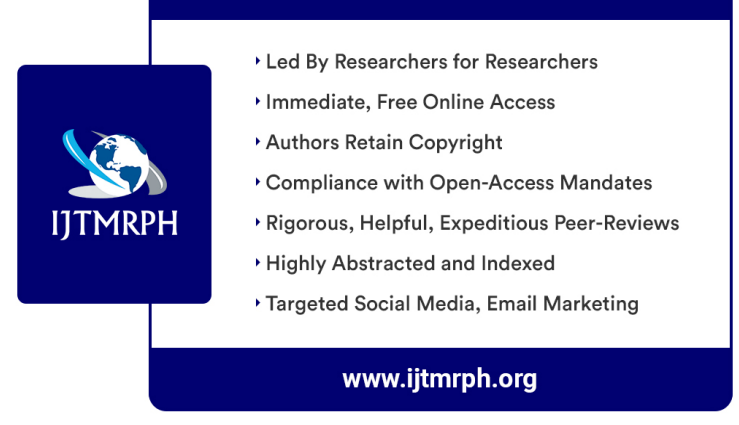

